\title{
BAHAN AJAR ELEKTRONIK (E-BOOK) KIMIA UMUM II BERBASIS KONTEKSTUAL MATERI LARUTAN
}

\author{
Julia Mardhiya ${ }^{1}$, Marudut Sinaga ${ }^{2}$ \\ ${ }^{1}$ Universitas Islam Negeri Walisongo Semarang \\ ${ }^{2}$ Universitas Negeri Medan \\ e-mail: ${ }^{1}$ julia.mardhiya@walisongo.ac.id
}

\begin{abstract}
Abstrak
Penelitian ini bertujuan untuk mengembangkan bahan ajar elektronik Kimia Umum II berbasis kontekstual materi larutan. Bahan ajar dikembangakan dengan cara mengintegrasikan media, eksperimen laboratorium, dan penerapan kontekstual yang berkaitan dengan materi yang diajarkan. Instrumen yang digunakan dalam penelitian ini yaitu bahan ajar kimia yang dikembangkan, kuesioner, dan tes evaluasi berupa pretest dan posttest. Hasil penilaian dari validator ahli dan responden mahasiswa menunjukkan bahwa bahan ajar valid dan tanpa revisi. Hasil rata-rata penilaian kelayakan isi 3,53; kelayakan bahasa 3,56; kelayakan penyajian 3,53; kelayakan kegrafikan 3,70. Sehingga penilaian akhir bahan ajar 3,58 berada pada rentang 3,26 - 4,00 yang menujukkan bahwa validator ahli dan mahasiswa menyatakan bahwa bahan ajar kimia yang diajukan valid dan tidak perlu dilakukan revisi kembali. Pada tahap implementasi menggunakan desain Pretest-Posttest Control Group Design, hasil belajar siswa pada kelas eksperimen $(M=75,00)$ lebih tinggi dari pada hasil belajar siswa pada kelas kontrol $(M=59,66)$. Sehingga dapat disimpulkan bahwa bahan ajar efektif digunakan untuk pembelajaran.
\end{abstract}

Kata kunci: bahan ajar elektronik, kontekstual, larutan

\begin{abstract}
This study aims to develop contextual General Chemistry II teaching materials on the subject of solutions. Teaching materials are developed by integrating media, laboratory experiments, and contextual application. The instruments are chemistry learning materials, questionnaires, pretest and posttest. Evaluation results from expert validators and student respondents show the teaching material is valid. Average results content feasibility 3.53; language feasibility 3,56; presentation feasibility 3.53; graphic feasibility 3.70. The final value of teaching material is 3.58 depending on the range 3.26 - 4.00. At the implementation stage with the Pretest-Posttest Control Group Design, the student learning outcomes in the experimental class $(M=75.00)$ were higher than the student learning outcomes in the control class $(M=59.66)$. So that teaching material developed can be used for learning.
\end{abstract}

Keywords: electronicteaching material, contextual, solution

\section{Pendahuluan}

Dewasa ini dunia telah mengalami berbagai perubahan yang cepat dalam hal kemajuan teknologi, globalisasi, inovasi dalam sains, meningkatnya tuntutan dunia kerja dengan berbagai kompetesi yang harus dimiliki. Semua perubahan ini mengharuskan pendidik untuk menyusun kembali berbagai keterampilan dan pengetahuan yang diperlukan siswa agar dapat menghadapi berbagai perubahan dan berkontribusi di dalam kehidupan bermasyarakat [1]. Kemampuan memahami secara kontekstual juga menjadi meningkat kepentingannya di tempat kerja. Semakin banyak pekerjaan yang menuntut keterampilan tingkat tinggi, memerlukan sumber daya manusia yang mampu belajar, berpikir kreatif, bernalar dan memecahkan masalah. Pendekatan berbasis kontekstual dalam pengajaran kimia diperlukan dalam menyajikan konsep ilmiah dan membangun hubungan dengan kehidupan sehari-hari [2]. 
Bahan ajar sebagai sumber belajar memainkan peran penting dalam pengajaran dan pembelajaran di kelas [3][4]. Bahan ajar yang bagus menyediakan informasi yang dapat membantu siswa untuk memahami teori konsep serta mengarahkan mahasiswa berpikir, berperilaku dan berkembang [5]. Bagi mahasiswa pendidikan tinggi bahan ajar sangat penting dalam proses belajar mengajar karena dapat memperkuat dan mendukung materi informasi yang disampaikan oleh pendidik di kelas. Bahan ajar dapat membantu mahasiswa untuk mempelajari materi kompleks yang belum diperoleh di kelas. Informasi ilmiah dalam bahan ajar dapat dipelajari berulang kali untuk mencapai kompetensi yang diinginkan [6]. Bahan ajar juga dituntut mengikuti era digital saat ini, bahan ajar digital (ebook) menjawab hal tersebut dimana ebook tidak hanya sekedar gambar dan tulisan namun dapat diintegrasikan dengan video dan feature lainnya yang dapat membuat pembeljaran menjadi lebih menarik[7].

Kurikulum pendidikan MIPA S1 memuat beberapa matakuliah yang wajib diambil oleh semua mahasiswa dari semua jurusan, yang dikenal dengan program bersama. Program bersama ini dimaksudkan untuk membina landasan berpikir yang sama serta mengembangkan wawasan yang luas mengenai rumpun ilmu MIPA. Program bersama ini sekaligus berfungsi sebagai wahana bagi pengembangan sikap ilmiah, serta pembinaan cara belajar di perguruan tinggi.

Salah satu mata kuliah wajib bersama bagi mahasiswa S1 Fakultas Matematika dan Pengetahuan Alam (FMIPA) adalah Kimia Umum I dan Kimia Umum II. Kimia Umum II membahas tentang Struktur Atom, Kesetimbangan Kimia, Larutan, reaksi Redoks dan lain-lain. Materi kuliah Kimia Umum II, khususnya pada materi Larutan yang mencakup sifat fisis larutan, kelarutan dan asam basa. Berdasarkan hasil observasi diketahui bahwa alokasi waktu materi ini tidak sesuai dengan banyaknya materi yang harus dipelajari mahasiswa. Kesulitan tersebut juga dibuktikan dengan hasil belajar mahasiswa beberapa angkatan pada pokok bahasan larutan lebih rendah dibanding dengan topik yang lain. Ada beberapa hal yang menghambat proses pembelajaran diantaranya ketersediaan bahan ajar yang menunjang mata kuliah Kimia Umum II terutama selama ini terbatas jumlahnya dan pelaksanaan pembelajaran selama ini cenderung berpusat pada dosen oleh karena itu perlu adanya bahan pembelajaran yang berkualitas, berbasis kontekstual dan serta sesuai dengan karakteristik dan kebutuhan mahasiswa terutama bagi mahasiswa S1 Pendidikan Kimia FMIPA Universitas Negeri Medan. Pemecahan masalah diatas dapat ditangani dengan pengadaan bahan ajar yang sesuai dengan kebutuhan dan karakteristik mahasiswa. Bahan ajar sebagai media pembelajaran yang efektif dalam kegiatan belajar mengajar yang mengarah pada pencapaian tujuan dan kompetensi mahasiswa. Presentasi dalam bahan ajar diharapkan berisi kegiatan yang menjadi sumber belajar mahasiswa [8].

\section{Metode Penelitian}

Penelitian ini termasuk penelitian pengembangan. Pengembanga dilakukan dengan cara pengayaan materi kimia larutan berbasis kontekstual yang dikemas menjadi bahan ajar dalam bentuk cetak dan elektronik, integrasi teknologi informasi pada sumber kontekstual secara online yang sesuai dengan materi kimia larutan, evaluasi dan standarisasi bahan ajar berdasarkan standar isi BSNP, dan implemenasi bahan ajar hasil pengembangan untuk meningkatkan hasil belajar mahasiswa pada pengajaran larutan. Model penelitian pengembangan yang akan digunakan dalam penelitian ini adalah model ADDIE (Analysis, Design, Development, Implementation, dan Evaluation). Penelitian dilakukan di Fmipa Unimed pada semester genap. Objek penelitian adalah pengembangan bahan ajar yang dipergunakan sebagai materi rujukan oleh mahasiswa dalam perkuliahan, para dosen Jurusan Kimia yang dikategorikan sebagai dosen ahli dalam bidang kimia dan pengajaran kimia, dan mahasiswa Kuliah Bersama FMIPA (8 Prodi) yang sedang belajar pada semester berjalan. Prosedur penelitian terdiri atas persiapan penelitian, penyusunan instrumen penelitian, pelaksanaan penelitian, pengumpulan data, dan analisis data hasil penelitian. Pada tahap implementasi digunakan disain PretestPosttest Control Group Design yang terdiri dari kelompok eksperimen dan kelompok kontrol. Siswa terdiri dari dua kelas yaitu kelas A (kelompok ekperimen) dan kelas B (kelompok kontrol).

Instrumen yang digunakan dalam penelitian ini adalah: (1) Bahan ajar yang dikembangkan, (2) Perangkat kuesioner standar, dan (3) Tes evaluasi untuk pretest dan posttest. Satu set tes evaluasi berisi 20 soal didistribusikan dengan variasi dari pertanyaan sederhana hingga sulit. Pertanyaan-pertanyaan itu dirancang untuk mencakup materi larutan dan dapat mengukur prestasi siswa dalam bidang kimia. 


\section{Hasil dan Pembahasan}

\subsection{Hasil Pengembangan Bahan Ajar Berbasis Kontekstual}

Bahan ajar larutan berbasis kontekstual terdiri dari Kompetensi Dasar (KD), capaian pembelajaran yang ingin dicapai, petunjuk penggunaan bahan ajar, rincian dari bahan ajar yang terdiri dari pengenalan singkat materi, masalah yang dapat didiskusikan oleh mahasiswa, contoh soal dan pemecahannya, penerapan materi dalam kehidupan sehari-hari, video eksperimen, kegiatan eksperimen yang dapat dilakukan oleh mahasiswa di laboratorium, latihan soal, rangkuman, glosarium, dan kunci jawaban dan Informasi tentang kimia dan kehidupan.

Bahan ajar berbasis kontekstual pada pokok bahasan larutan hasil pengembangan terdiri atas sub pokok bahasan yang disusun sesuai dengan tuntutan silabus Kimia Umum II. Masing-masing sub pokok bahasan tersebut disusun sesuai dengan perkembangan peserta didik dilanjutkan dengan integrasi inovasi pembelajaran melalui media pembelajaran berupa video, virtual laboratory online, dan media weblog. Model pembelajaran yang digunakan adalah model pembelajar Contextual Teaching Learning, serta dicantumkan contoh kasus dalam kehidupan sehari-hari, kegiatan luar dan kegiatan laboratorium.

Tabel 1. Daftar Pengembangan Sub Bahasan Pada Bahan Ajar

\begin{tabular}{|c|c|c|c|}
\hline No & \multicolumn{2}{|c|}{$\begin{array}{l}\text { Pokok bahasan / Sub } \\
\text { Pokok Bahasan }\end{array}$} & Komponen yang dikembangkan \\
\hline & \multicolumn{2}{|c|}{ Larutan } & $\begin{array}{l}\text { Capain pembelajaran, pendahuluan, peta konsep, materi, contoh soal, } \\
\text { soal latihan rangkuman, kunci iawaban glosarium. }\end{array}$ \\
\hline 1 & $\begin{array}{l}\text { Larutan dan } \\
\text { sifatnya }\end{array}$ & Sifat- & $\begin{array}{l}\text { - Diberikan masalah dahulu sebelum masuk ke topik bahasan } \\
\text { - Materi lebih singkat dan jelas } \\
\text { - Dilengkapi contoh soal dan soal latihan } \\
\text { - Kegiatan praktikum atau penemuan } \\
\text { - Contoh aplikasi keseharian }\end{array}$ \\
\hline 2 & Asam dan Basa & & $\begin{array}{l}\text { - Materi lebih singkat dan jelas } \\
\text { - Menampilkan contoh soal dan soal latihan } \\
\text { - Menyajikan data hasil percobaan untuk dianalisis } \\
\text { - Diberikan media video } \\
\text { - Contoh aplikasi keseharian } \\
\text { - Kegiatan luar kelas, dan tugas }\end{array}$ \\
\hline 3 & $\begin{array}{l}\text { Kesetimbangan } \\
\text { dalam Larutan }\end{array}$ & Ion & $\begin{array}{l}\text { - Diberikan masalah dahulu sebelum masuk ke topik bahasan } \\
\text { - Materi lebih singkat dan jelas } \\
\text { - Menampilkan contoh soal } \\
\text { - Diberikan media video } \\
\text { - Contoh aplikasi keseharian } \\
\text { - Kegiatan luar kelas, dan tugas }\end{array}$ \\
\hline
\end{tabular}

Pengadaan media pembelajaran di atas diperuntukkan menolong mahasiswa dalam memahami bahan ajar sedangkan model pembelajaran tersebut dipergunakan agar para mahasiswa lebih aktif dan lebih termotivasi dalam memahami pembelajaran. Pada tahap akhir pengembangan disusun soal evaluasi yang dapat mengukur kompetensi mahasiswa terhadap materi. Pengembangan bahan ajar dari buku kimia meliputi fase pokok sebagai berikut: menganalisis standar kompetensi dan kompetensi dasar yang ada dalam silabus kimia umum II, menganalisis buku teks yang digunakan sebagai bahan ajar di perguruan tinggi tempat penelitian dan juga buku terbitan lain, kemudian hasil analisis digunakan sebagai referensi untuk membuat bahan ajar dengan mengembangkan kegiatan praktikum, kegiatan luar sekolah, dan media yang sesuai.

Pendekatan kontekstual yang digunakan dalam pengembangan bahan ajar ini diterapkan dengan cara memperbanyak penjelasan dengan kontruktivisme dalam membangun dan menyusun pengetahuan baru mahasiswa. Selanjutnya melakukan kegiatan inkuiri dan membuat pertanyaan yang dapat merangsang mahasiswa untuk berpikir. Dalam bahan ajar ini juga ditambahkan feature Kimia dan Kehidupan agar mahasiswa dapat memahami keterkaitan antara materi yang dipelajari dengan kehidupan nyata. 


\subsection{Standarisasi Bahan Ajar}

Penilaian Bahan ajar Kimia Umum II berbasis kontekstual materi larutan dilakukan oleh validator ahli dan responden mahasiswa yang telah melalui mata kuliah Kimia Umum II. Hasil rata - rata yang diperoleh untuk masing - masing analisis standar kelayakan yang diajukan kepada validator ahli dan mahasiswa yaitu 3,58 berada pada kisaran 3,26 - 4,00 yang berarti bahwa validator ahli dan mahasiswa menyatakan bahwa bahan ajar kimia yang diajukan valid dan tidak perlu dilakukan revisi. Bahan ajar kimia dapat digunakan dalam pembelajaran kimia di Perguruan Tinggi.

Tabel 2. Hasil Standarisasi Bahan Ajar

\begin{tabular}{|c|c|c|c|c|}
\hline \multirow{2}{*}{$\begin{array}{c}\text { Unsur } \\
\text { Penilaian }\end{array}$} & \multirow[b]{2}{*}{ Komponen Yang dinilai } & \multicolumn{2}{|c|}{ Rentang Validitas } & \multirow[b]{2}{*}{$\begin{array}{l}\text { Rata- } \\
\text { Rata }\end{array}$} \\
\hline & & $\begin{array}{c}\mathrm{D} \\
(\mathrm{n}=5)\end{array}$ & $\begin{array}{c}M \\
(n=40)\end{array}$ & \\
\hline \multirow{7}{*}{ Kelayakan Isi } & Cakupan materi & 3,60 & 3,40 & 3,50 \\
\hline & Keakuratan materi & 3,71 & 3,38 & 3,55 \\
\hline & Kemuktahiran materi & 3,67 & 3,43 & 3,55 \\
\hline & Wawasan produktivitas & 3,40 & 3,48 & 3,44 \\
\hline & Stimulasi keingintahuan & 3,70 & 3,50 & 3,60 \\
\hline & Kecakapan hidup & 3,75 & 3,40 & 3,58 \\
\hline & Wawasan Ke-Indonesiaan & 3,40 & 3,55 & 3,48 \\
\hline \multicolumn{2}{|c|}{ Rata-Rata Kelayakan Isi } & 3,60 & 3,45 & 3,53 \\
\hline \multirow{7}{*}{$\begin{array}{c}\text { Kelayakan } \\
\text { Bahasa }\end{array}$} & $\begin{array}{l}\text { Sesuai dengan perkembangan } \\
\text { mahasiswa }\end{array}$ & 3,70 & 3,43 & 3,57 \\
\hline & Komunikatif & 3,60 & 3,43 & 3,52 \\
\hline & Dialogis dan interaktif & 4,00 & 3,43 & 3,72 \\
\hline & Lugas & 3,60 & 3,40 & 3,50 \\
\hline & Koherensi dan runut & 3,47 & 3,45 & 3,46 \\
\hline & Sesuai EYD & 3,70 & 3,45 & 3,58 \\
\hline & Penggunaan istilah dan simbol & 3,90 & 3,33 & 3,62 \\
\hline \multicolumn{2}{|c|}{ Rata-Rata Kelayakan Bahasa } & 3,71 & 3,42 & 3,56 \\
\hline \multirow{3}{*}{$\begin{array}{c}\text { Kelayakan } \\
\text { penyajian }\end{array}$} & Teknik penyajian & 3,54 & 3,48 & 3,51 \\
\hline & Pendukung penyajian materi & 3,57 & 3,45 & 3,51 \\
\hline & Penyajian pembelajaran & 3,66 & 3,45 & 3,56 \\
\hline \multicolumn{2}{|c|}{ Rata-rata Kelayakan Penyajian } & 3,59 & 3,46 & 3,53 \\
\hline \multirow{3}{*}{$\begin{array}{l}\text { Kelayakan } \\
\text { kegrafikaan }\end{array}$} & Ukuran buku & 3,80 & 3,68 & 3,74 \\
\hline & Desain buku & 3,52 & 3,70 & 3,61 \\
\hline & Tipografi Buku & 3,80 & 3,70 & 3,75 \\
\hline \multicolumn{2}{|c|}{ Rata-Rata Kelayakan Kegrafikan } & 3,71 & 3,69 & 3,70 \\
\hline
\end{tabular}

\subsection{Implementasi Bahan Ajar}

Bahan ajar hasil pengembangan selanjutnya diimplementasikan di dalam kelas pada materi Larutan. Hasil belajar mahasiswa diperoleh dari kemampuan mahasiswa dalam menjawab pretest dan posttest. Berdasarkan hasil dan analisis data penelitian yang telah dilaksanakan pada kedua kelas sampel yaitu kelas A sebagai kelas eksperimen dan kelas B sebagai kelas kontrol, maka diperoleh data hasil belajar kognitif mahasiswa. Dari Tabel 3, terlihat bahwa perolehan hasil belajar kognitif kelas eksperimen lebih tinggi dari kelas kontrol. Untuk membuktikan apakah hasil tes kognitif kedua kelas sampel yang diperoleh berbeda secara signifikan atau tidak, maka dilakukan uji hipotesis. Uji normalitas dan uji homogenitas dilakukan sebelum uji hipotesis.

Untuk melakukan uji normalitas, data yang digunakan adalah nilai pre-test, post-test, dan gain setiap siswa di kelas eksperimen dan kelas kontrol. Uji normalitas dihitung dengan SPSS 20 for windows program menggunakan Kolmogorov-Smirnov, dengan $\alpha=0,05$. Jika harga Sig. $>\alpha$, berarti data sampel normal. Hasil uji normalitas data di kedua kelas terdapat pada Tabel 4. 
Tabel 3. Rata-rata hasil belajar mahasiswa

\begin{tabular}{lcc}
\hline \multirow{2}{*}{ Jenis Evaluasi } & \multicolumn{2}{c}{ Rata-rata Hasil Belajar mahasiswa } \\
\cline { 2 - 3 } & Kontrol & Eksperimen \\
\hline Pretest & 19,67 & 24,33 \\
Posttest & 59,66 & 75,00 \\
\hline
\end{tabular}

Tabel 4. Hasil uji normalitas data

\begin{tabular}{clccc}
\hline Kelas & \multicolumn{1}{c}{ Data } & Sig. & A & Keterangan \\
\hline \multirow{3}{*}{ Kontrol } & Pre-test & 0,225 & 0,05 & Data normal \\
& Post-test & 0,799 & 0,05 & Data normal \\
& Gain & 0,997 & 0,05 & Data normal \\
& Pretes & 0,771 & 0,05 & Data normal \\
Eksperimen & Postes & 0,684 & 0,05 & Data normal \\
& Gain & 0,940 & 0,05 & Data normal \\
\hline
\end{tabular}

Uji homogenitas data bertujuan untuk mengetahui apakah kedua data yang berasal dari sampel bersifat homogen. Perhitungan uji homogenitas dengan menggunakan uji Levene test pada program SPSS 20 pada $\alpha=0,05$. Jika harga Sig. $>\alpha$, berarti kedua kelompok sampel berasal dari populasi yang homogen.

Tabel 5. Hasil uji homogenitas data

\begin{tabular}{lccc}
\hline \multicolumn{1}{c}{ Data } & Sig. & $\boldsymbol{\alpha}$ & Keterangan \\
\hline Pretest & 0,226 & 0,05 & Data Homogen \\
Posttest & 0,382 & 0,05 & Data Homogen \\
Gain & 0,302 & 0,05 & Data Homogen \\
\hline
\end{tabular}

Pengujian hipotesis dilakukan dengan SPSS 20 menggunakan Independent Sample T-Test one tailed $t$-test pada tingkat signifikansi $\alpha=0,05$ dan tingkat kepercayaan sebesar $95 \%$, jika data yang didapat $<$ 0,05 maka Ha diterima sedangkan Ho ditolak. Berdasarkan uji Independent Sample T-Test one tailed t-test menunjukkan bahwa harga Sig. $\alpha 0,033<0,05$, maka Ha diterima. Hal ini menunjukkan bahwa ada perbedaan yang signifikan (nyata) antara rata-rata hasil belajar mahasiswa kelas kontrol dan kelas eksperimen.

\subsection{Pembahasan}

Bahan ajar kimia berbasis kontekstual dapat membantu siswa untuk belajar kimia. Hal ini terlihat adanya respon positif dari mahasiswa. Bahan ajar yang dikembangkan memadai untuk digunakan sebagai sumber pengetahuan yang membuat mahasiswa meningkatkan kemampuan kompetensi kimianya. Feature yang terintegrasi pada bahan ajar efektif untuk komunikasi ilmiah pada kegiatan pembelajaran. Contoh yang disediakan dalam materi pembelajaran cukup untuk membimbing mahasiswa belajar dan untuk memecahkan masalah kimia yang berkaitan dengan topik larutan. Kumpulan percobaan laboratorium yang terintegrasi dalam materi pembelajaran (melalui e-book) dapat dilihat oleh mahasiswa, dan dapat membantu mahasiswa memperluas pengetahuan dan pemahaman mereka terkait dengan teori yang diberikan tanpa melakukan percobaan di laboratorium. Namun, jika mahasiswa yang tertarik untuk melakukan percobaan langsung dapat menggunakan bahan di laboratorium karena dilengkapi dengan intruksi yang memadai untuk melakukan percobaan di laboratorium disertai dengan lembar data laboratorium [9].

Video eksperimen laboratorium dapat digunakan sebagai media pembelajaran yang dapat dilihat berkali-kali oleh siswa. Konten ilmiah dalam video yang relevan akan membantu mahasiswa memahami subjek dengan jelas sebelum mereka melakukan percobaan nyata di laboratorium. Studi kasus dan hyperlink ke situs web yang relevan membuat siswa mudah menghubungkan mata pelajaran yang relevan. Penambahan kegiatan belajar aktif diperlukan untuk membantu siswa untuk belajar 
berdasarkan kebutuhan mereka [11]. Bahan ajar dlam bentuk cetak dan elektronik dalam format flipbook pada bahan ajar yang dikembangkan mampu memfasilitasi siswa untuk memilih pembelajaran mereka karena penelitian telah menunjukkan bahwa pengajaran dan pembelajaran interaktif dapat membantu siswa untuk belajar [12] [13].

Dalam penelitian ini dikeahui bahwa bahan ajar yang dikembangkan telah memenuhi kriteria buku standar. Semua responden memberikan pendapat positif terhadap bahan ajar (rata-rata 3,58). Bahan ajar juga telah terbukti dapat meningkatkan prestasi siswa dalam mata kuliah kimia. Hasil implementasi menunjukkan bahwa prestasi tinggi siswa di bidang kimia dicapai ketika menerapkan bahan ajar dalam proses pengajaran. Pencapaian rata-rata di kelas eksperimen $(M=75,00)$ lebih tinggi daripada di kelas kontrol $(M=59,66)$. Hasil penelitian yang mendukung menemukan bahwa buku teks berkualitas baik dapat digunakan sebagai sumber informasi terkait dengan topik yang mereka pelajari [14]. Bahan ajar telah memberikan informasi ilmiah yang memadai yang dapat dilakukan membantu siswa untuk memahami teori konsep [15]. Ketersediaan bahan ajar elektronik untuk digunakan menyelesaikan masalah setiap saat ketika ditemukan kesulitan dalam belajar kimia. Demikian juga hasil-hasil penelitian yang relevan menunjukkan bahwa model pembelajaran kontekstual efektif meningkatkan kualitas dan hasil belajar siswa [16]. Pendekatan kontekstual dapat meningkatkan kemampuan analisis mahasiswa dan mendapat respon yang positif dari mahasiswa [17].

\section{Kesimpulan}

Bahan ajar Laruan berbasis konteksual telah dikembangkan dan distandarisasi dan memenuhi standar nasional. Bahan ajar didesain melalui pengayaan bahan kimia dengan konten lokal. Inovasi dari bahan ajar melalui integrasi percobaan laboratorium, aplikasi kontekstual, integrasi media pada ebook dan hyperlink situs web yang relevan. Materi pembelajaran kimia yang inovatif dirancang dalam format yang menarik dan disediakan dalam bentuk cetak dan ebook untuk memudahkan siswa memilih bahan yang tepat pada pembelajaran kimia tergantung pada kebutuhan mereka. Bahan ajar yang dikembangkan membantu siswa untuk belajar kimia dengan mudah dan terbukti dapat meningkat prestasi mahasiswa pada pokok bahasan larutan.

\section{Daftar Pustaka}

[1] Wilmarth, S. Five socio-technology trends that change everything in learning and teaching. Curriculum. 2010; 21: 80-96.

[2] Magwilang, E. B. Teaching chemistry in context: Its effects on students' motivation, attitudes and achievement in chemistry. International Journal of Learning, Teaching and Educational Research. 2016; 15(4): 60-68.

[3] Abed, E. R., \& Al-Absi, M. M.. Content Analysis of Jordanian Elementary Textbooks during 1970-2013 as Case Study. International Education Studies. 2015; 8(3): 159-166.

[4] Sinatra, G. M., \& Broughton, S. H.Bridging Reading Comprehension and Conceptual Change in Science Education: The Promise of Refutation Text. Reading Research Quarterly. 2011; 46(4): 374-393

[5] Chambliss, M. J. Analyzing science textbook materials to determine how "persuasive" they are. Theory into Practice. 2001; 40(4): 255-264.

[6] Good, J. J., Woodzicka, J. A., \& Wingfield, L. C. The Effects of Gender Stereotypic and CounterStereotypic Textbook Images on Science Performance. The Journal of Social Psychology. 2010: 150(2): 132-147.

[7] Ericson, B. J., Guzdial, M. J., \& Morrison, B. B. Analysis of interactive features designed to enhance learning in an ebook. In Proceedings of the eleventh annual International Conference on International Computing Education Research. 2015: 169-178

[8] Tompkins, C. J., Rosen, A. L., \& Larkin, H. Guest Editorial: An Analysis of Social Work Textbooks for Aging Content: How Well Do Social Work Foundation Texts Prepare Students for Our Aging Society? Journal of Social Work Education. 2006; 42(1); 3-24.

[9] Situmorang, M., Sitorus, M., Hutabarat, W., \& Situmorang, Z. The Development of Innovative Chemistry Learning Material for Bilingual Senior High School Students in Indonesia. International Education Studies. 2015; 8(10): 72-85. 
[10] Marshall, L. L., \& Nykamp, D. Active-learning assignments to integrate basic science and clinical course material. American journal of pharmaceutical education. 2010: 74(7): 1-5.

[11] Baron, A., \& Chen, H. L. S. Looking in a science classroom: exploring possibilities of creative cultural divergence in science teaching and learning. Cultural Studies of Science Education. 2012: 7(1): 93-101.

[12] Holmes, M. H. Integrating the learning of mathematics and science using interactive teaching and learning strategies. Journal of Science Education and Technology. 2006: 15(3-4): 247-256.

[13] Carter, J. L., \& Mayer, W. V. Reading beyond the textbook: Great books of biology. BioScience. 1988; 38(7): 490-492.

[14] Chambliss, M. J. Analyzing Science Textbook Materials to Determine How äPersuasiveä They Are. Theory into Practice. 2001; 40(4): 255-264.

[15] Sabil, H. Penerapan Pembelajaran Contextual Teaching \& Learning (CTL) Pada Materi Ruang Dimensi Tiga menggunakan Model pembelajaran Berdasarkan Masalah (MPBM) Mahasiswa Program Studi Pendidikan Matematika FKIP UNJA. Jurnal Edumatica, 2013: 1(1): 44-46.

[16] Nurdiyana, T. Peningkatan kemampuan analisis mahasiswa melalui pendekatan contextual teaching learning (CTL) dalam pembelajaran Pengantar Kependudukan. Vidya Karya. 2019; 27(1): $71-78$ 